\title{
Magnesium whitlockite deposition in articular cartilage: a study of 80 specimens from 70 patients
}

\author{
Colin A Scotchford, S Yousuf Ali
}

\begin{abstract}
Objective-To examine articular cartilage from a number of joint sites, using a large sample group, for the presence of magnesium whitlockite crystal deposition.

Methods-Articular cartilage specimens were taken from a total of 70 patients. The majority of specimens were taken from femoral heads, with smaller numbers from femoral condyle, tibial plateau, radius, ulna, and several small peripheral joints. Normal and osteoarthritic articular cartilage specimens were obtained from patients undergoing prosthesis replacement or amputation. Specimens were resin embedded and examined using transmission electron microscopy and $x$ ray microanalysis.

Results-Magnesium whitlockite crystals were identified, on the basis of morphology, size and elemental composition, in articular cartilage from all sites sampled. The distribution of crystals was similar in all samples (restricted to the superficial zone), although the density of deposition was extremely variable, with the greatest density observed in femoral head specimens. No magnesium whitlockite crystals were observed in osteophytic or epiphysial cartilage.

Conclusions-This study demonstrated the widespread extent of magnesium whitlockite deposition in human articular cartilage, albeit at much lower density than previously reported in femoral head articular cartilage. In consideration of possible roles for these crystals in articular cartilage, it is concluded that an opportunistic mode of formation, possibly influenced by mechanical stresses, would be most plausible.
\end{abstract}

Institute of

Orthopaedics,

University College

London Medical

School,

Royal National

Orthopaedic Hospital,

Stanmore,

United Kingdom

C A Scotchford

$S$ Y Ali

Correspondence to:

Professor S Y Ali,

Institute of Orthopaedics,

Royal National Orthopaedic

Hospital,

Brockley Hill,

Stanmore,

Middlesex HA7 4LP

United Kingdom.

Accepted for publication

16 December 1994
(Ann Rheum Dis 1995; 54: 339-344)

Arthropathies associated with monosodium urate (MSU) and calcium pyrophosphate dihydrate (CPPD) deposition are well established. ${ }^{12}$ More recently, basic calcium phosphate (BCP) crystals, including hydroxyapatite, ${ }^{3}$ carbonated apatites ${ }^{4}$ and octocalcium phosphate, ${ }^{4-6}$ have been assigned a role in crystal arthropathy. ${ }^{3} 7$

BCP crystal deposition takes place at two main articular sites, periarticular tendon ${ }^{8}$ and intra-articular cartilage. ${ }^{3910}$ In articular cartilage, apatite crystals tend to be deposited in smaller amounts than in tendon, ${ }^{10}$ and demon- strate a pericellular distribution associated with an extension of the calcified zone. ${ }^{10} 11$ BCP crystals have been reported in the synovial fluid of approximately $30 \%$ of patients in a number of studies. ${ }^{32-14}$ Several patterns of arthritis have been associated with BCP crystals, including primary arthritis, polyarticular arthritis and Milwaukee shoulder syndrome. The deposition of BCP crystals in articular cartilage may be a secondary event resulting from other changes in cartilage metabolism or structure. Their presence, however, may induce further damage to the tissue by feedback mechanisms resulting in an amplification loop. ${ }^{15}$ Support for such a relationship may be drawn from a number of studies. The severity of knee joint degeneration has been correlated with hydroxyapatite concentration in synovial fluid ${ }^{12} 16$ and a rapidly progressive destructive disease of the shoulder associated with hydroxyapatite deposition has been described. ${ }^{17} 18$

Anomalous calcium phosphate 'cuboid' crystals were first described in osteoarthritic and elderly human articular cartilage. ${ }^{9} 101920$ On the basis of their calcium to phosphorus ratio and morphology, they were postulated to be magnesium whitlockite. ${ }^{1021}$ More recently, crystals having the same morphology, size range and calcium to phosphorus ratio were reported in osteoarthritic (OA) articular cartilage from nine of 19 patients ${ }^{22}$ and consistently, in a study of normal human femoral head articular cartilage, in all of 12 patients across a broad age range. ${ }^{23}$ Crystal density was significantly greater in superior region samples than inferior region samples; this difference was smaller in older specimens. A band of crystals $10-20 \mu \mathrm{m}$ below the articular surface was observed in superior region samples. Using electron and $x$ ray diffraction techniques, these crystals have since been identified as magnesium whitlockite; the possibility of artefactual formation was discounted by using a variety of tissue preparation methods. ${ }^{24}$ Magnesium whitlockite is a basic calcium phosphate, similar to $\beta$-tri calcium phosphate, in which $\mathrm{Mg}^{2+}, \mathrm{H}_{2} \mathrm{O}$ and $\mathrm{HPO}_{4}{ }^{2-}$ play a structural role. ${ }^{25}$

In this study, normal articular cartilage from an extensive range of patients and joint sites has been examined for magnesium whitlockite crystal deposition.

\section{Materials and methods}

SPECIMENS

Articular cartilage specimens were taken from a total of 70 patients. The majority of 
specimens were normal femoral head articular cartilage, resected because of tumour located distant from the sampled cartilage, or fracture of femoral neck, or osteoarthritic cartilage from the same site. Cartilage was taken from other joint sites, when available, from patients having amputation or resection for bone tumour.

In all cases full depth blocks of articular cartilage, plus subchondral bone, were taken from sample sites. Specimens were generally obtained within 20 minutes of resection. Normal articular cartilage samples were taken from weight bearing regions of joints where possible. All tissues remained undecalcified.

\section{TRANSMISSION ELECTRON MICROSCOPY}

Tissue samples were subdivided to full depth blocks approximately $1 \mathrm{~mm}$ in the remaining two dimensions. A small amount of subchondral bone was left attached to minimise tissue distortion during processing and facilitate easy tissue orientation. The tissue blocks were fixed for two to four hours in $1.5 \%$ glutaraldehyde (Agar Scientific, Stansted, UK) in $0.085 \mathrm{~mol} / \mathrm{l}$ sodium cacodylate buffer ( $\mathrm{pH} 7 \cdot 4$ ) (Merck, Poole, UK). Specimens were then washed in three changes of $0.085 \mathrm{~mol} / \mathrm{l}$ sodium caco-

Table 1 Range of sample sites from which full depth articular cartilage specimens were taken, number of specimens obtained from each site listed, and age range and male to female ratio of patients. The extent of magnesium whitlockite crystal deposition is indicated on a presence/not observed basis, with a qualitative grading score for the density of deposition, as determined by transmission electron microscopy

\begin{tabular}{|c|c|c|c|c|c|}
\hline \multirow[t]{2}{*}{ Sample site } & \multirow{2}{*}{$\begin{array}{l}\text { No of } \\
\text { samples }\end{array}$} & \multirow{2}{*}{$\begin{array}{l}\text { Age range } \\
(y r)\end{array}$} & \multirow[t]{2}{*}{$M / F$} & \multicolumn{2}{|l|}{ No of samples } \\
\hline & & & & $\begin{array}{l}\text { Crystals } \\
\text { present (grade) }\end{array}$ & $\begin{array}{l}\text { Crystals } \\
\text { not observed }\end{array}$ \\
\hline Femoral head (normal) & 34 & $10-93$ & $14-20$ & $34(3-4)$ & - \\
\hline Femoral head (OA) & 26 & $46-83$ & $8 / 18$ & $26(1-2)$ & - \\
\hline Peripheral osteophyte & 5 & $53-73$ & $3 / 2$ & $-(0)$ & 5 \\
\hline Femoral condyle & 3 & $5-20$ & $2 / 1$ & $3(2)$ & - \\
\hline Tibial plateau & 2 & $19-20$ & $2 / 0$ & $2(1)$ & - \\
\hline Radial head & 1 & 19 & $1 / 0$ & 1 (3) & - \\
\hline Proximal ulna & 1 & 19 & $1 / 0$ & $1(3)$ & - \\
\hline 1st metatarsal & 2 & $17-61$ & $2 / 0$ & $2(1-2)$ & - \\
\hline Carpal & 1 & 19 & $1 / 0$ & $1(1)$ & - \\
\hline 2nd metacarpal & 2 & $19-62$ & $2 / 0$ & $2(1-2)$ & - \\
\hline Lunate & 2 & $19-62$ & $2 / 0$ & $2(1-2)$ & - \\
\hline Phalanges & 1 & 17 & $0 / 1$ & $1(1-2)$ & - \\
\hline Epiphysial growth plate & 1 & 9 & $1 / 0$ & $-(0)$ & 1 \\
\hline
\end{tabular}

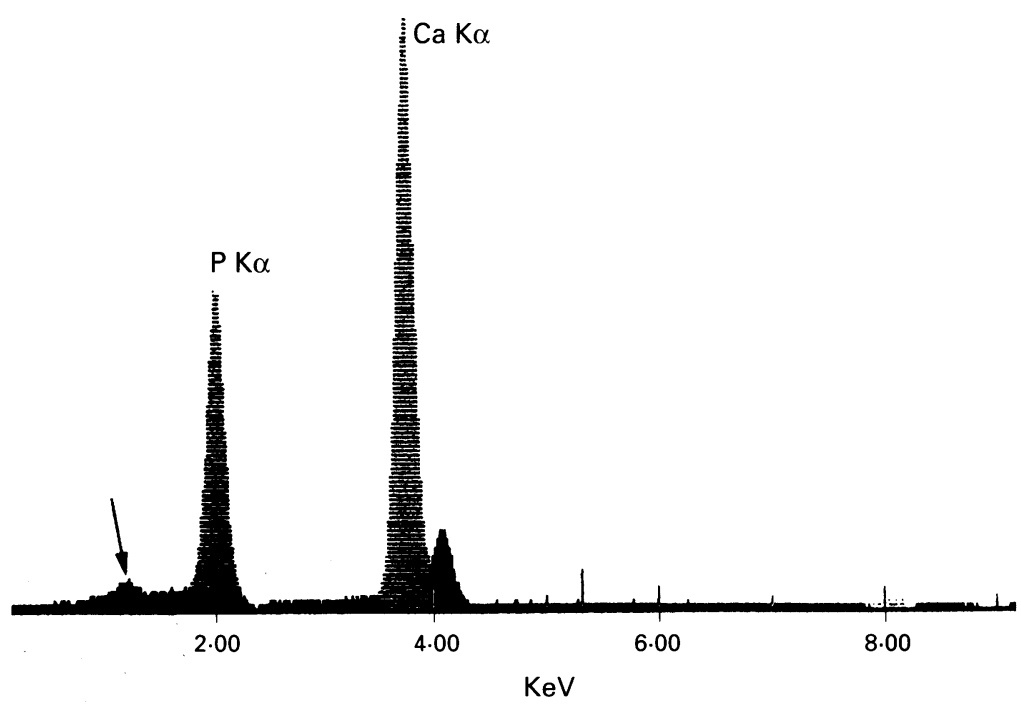

Figure 1 Characteristic $\mathrm{x}$ ray microanalysis spectrum from magnesium whitlockite crystal in human articular cartilage. Peaks for calcium, phosphorus and magnesium (arrow) are clearly present. dylate buffer containing $0.2 \mathrm{~mol} / \mathrm{l}$ sucrose (Merck) (pH 7.4) (wash buffer). The tissue blocks were then divided and half the blocks underwent secondary fixation with $1 \%$ osmium tetroxide (Agar Scientific) in $0.085 \mathrm{~mol} / 1$ sodium cacodylate for 90 minutes at room temperature. Buffer washing was repeated and all tissue blocks were dehydrated through a graded alcohol series. Specimens were transferred to propylene oxide (Agar Scientific) for 30 minutes before infiltration with a $1: 1$ propylene oxide:araldite CY212 resin (Agar Scientific) mixture for one hour, followed by infiltration in neat CY212 resin under vacuum (150 mbar) overnight, and embedding in fresh resin at $60^{\circ} \mathrm{C}$ for 48 hours. CY212 resin was mixed according to the manufacturer's instructions with the omission of methyl phthalate (plasticiser).

Ultrathin sections $(70-100 \mathrm{~nm})$ were cut with diatome diamond knives (Leica, Milton Keynes, UK) using a Reichert Ultracut E ultramicrotome (Leica) and floated onto $0.085 \mathrm{~mol} / 1$ sodium cacodylate buffer before collection on to G200 HS copper grids (TAAB Laboratories, Aldermaston, UK). Where necessary the grids were precoated with $0.45 \%$ piolform (Agar Scientific) in chloroform (Merck). If required, ultrathin sections were stained on drops of aqueous saturated uranyl acetate (Agar Scientific) for 10 minutes at room temperature followed by lead citrate for five minutes at room temperature in the presence of sodium hydroxide pellets (Merck).

\section{$X$ RAY MICROANALYSIS}

Unstained sections were examined using a Philips CM12 transmission electron microscope with an EDAX PV9800 $x$ ray microanalysis (XRMA) system. Spectra were recorded at $100 \mathrm{kV}$ (operation at maximum available $\mathrm{kV}$ has been recommended to obtain maximum peak to background ratios ${ }^{26}$ ), for 200 live seconds with a tilt angle of $20^{\circ}$, giving a total 'take off' angle of $40^{\circ}$. The electron probe size was selected to encompass individual crystals and was never greater than $200 \mathrm{~nm}$ diameter; a $70 \mathrm{~nm}$ 'top hat' condenser aperture was used to minimise the background effect of $x$ rays generated higher in the column reaching the specimen area. Calcium to phosphorus ratios were calculated using the quantitative analysis of thin sections software package (EDAX PV9800) based on the ratio model. ${ }^{27}$ The synthetic hydroxyapatite sample was used as the calcium phosphate standard for these analyses. ${ }^{28}$

\section{Results}

Crystals were observed in articular cartilage from all sites sampled (table 1). Identification was based on the distinctive 'cuboid' morphology, electron density, size range $(50-500 \mathrm{~nm})$ and XRMA spectrum, and the calcium to phosphorus ratio generated from this. Crystals from areas of deposition all generated spectra with characteristic calcium, phosphorus and magnesium peaks (fig 1). Calcium to phosphorus ratios ranged from 1.30 to 1.47 . 
The distribution in all cases was similar to that described for normal femoral head articular cartilage. ${ }^{23}$ Crystals were present either within a band running parallel to the articular surface from $5 \mu \mathrm{m}$ to a maximum of $50 \mu \mathrm{m}$ depth below the surface, or in close proximity to chondrocytes, and occasionally in dense clusters. A band of crystals was identified in many specimens with variable density and depth, frequently with a degree of patchiness. The depth of the band in some specimens was limited to extreme superficial articular cartilage extracellular matrix between the articular surface and the most superficial chondrocytes, a region frequently observed to

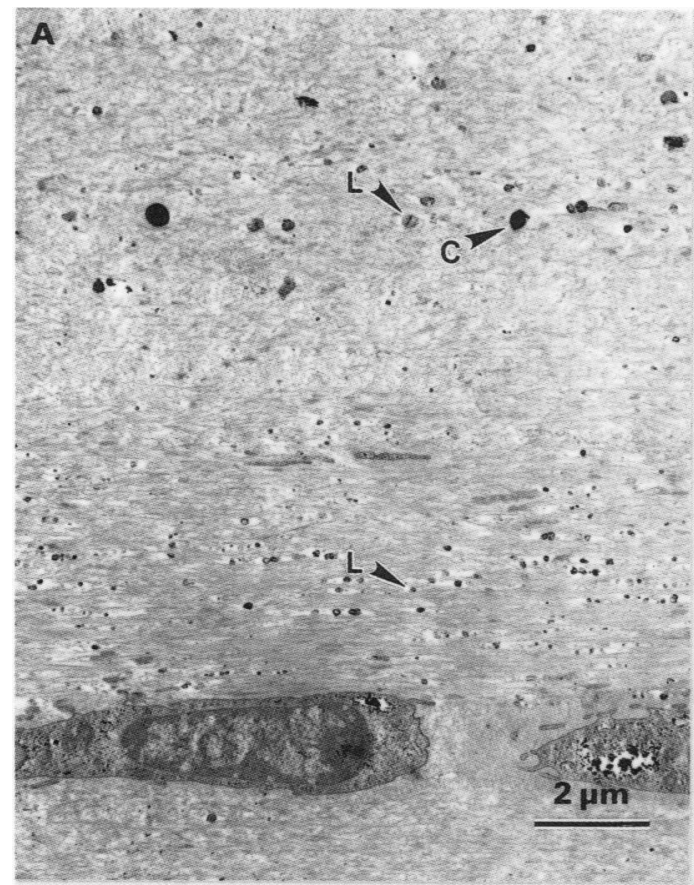

C

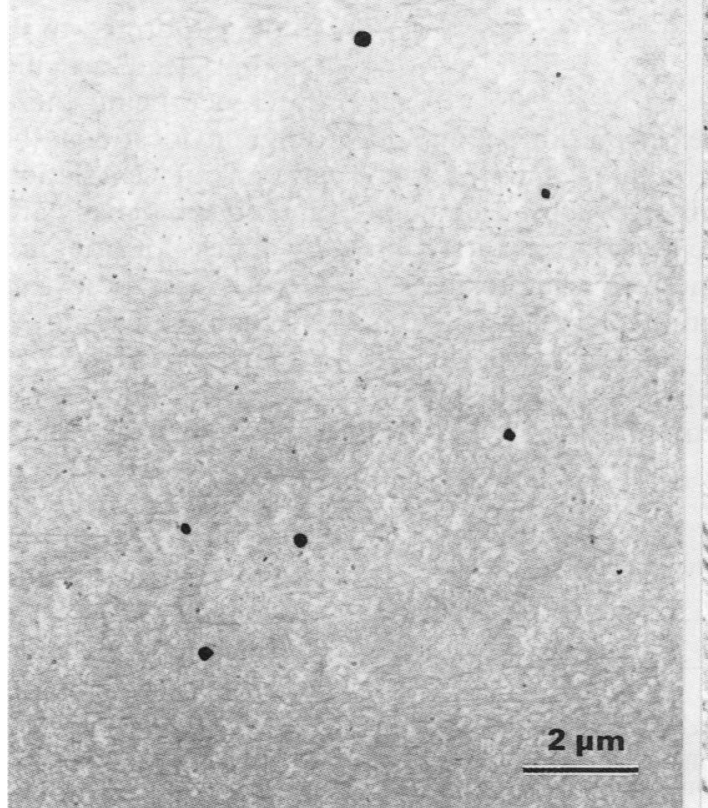

contain characteristic granular intramatrical lipidic debris, including membranous structures (fig 2A). Other specimens demonstrated a deepening of the band, encompassing initial superficial zone chondrocytes (fig 2B). Such differences between specimens appeared to be related to the age of the patient, specimens from older patients having deeper bands of crystal deposition. Crystals were commonly observed deposited pericellularly to chondrocytes, apparently associated with intramatrical lipidic debris (fig 2C). In many cases the crystal distribution was biased, with greater numbers adjacent to the articular surface aspect of the cells when viewed in sagittal
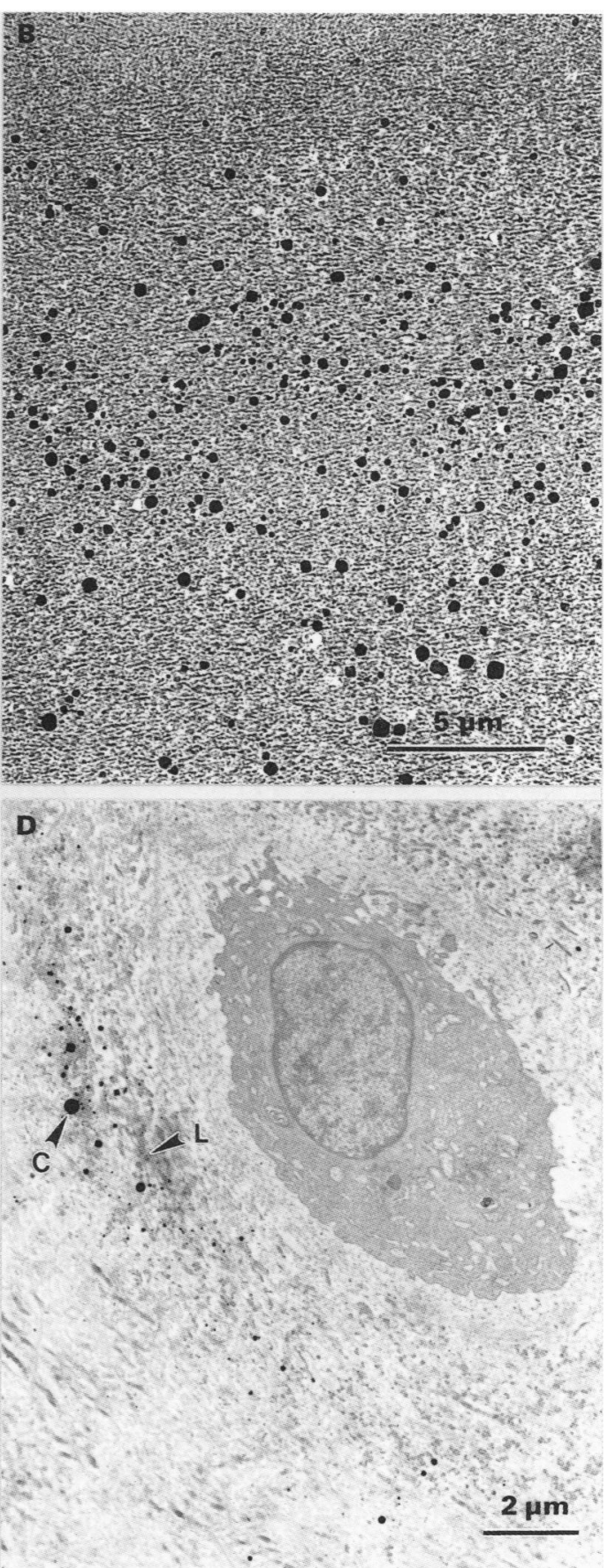

Figure 2 Transmission electron micrographs of magnesium whitlockite crystal deposition in human articular cartilage. A: Crystals (C) are present, forming a band immediately below the articular surface, together with intramatrical lipidic debris $(L)$. (Patient 20 years; femoral condyle; section stained with uranyl acetate and lead citrate.) B: Denser crystal deposition in femoral head articular cartilage shows a broader band. (Patient 43 years; femoral head; unstained section.) C: Sparse deposition in specimens of metacarpal articular cartilage. (Patient 19 years; unstained section.) D: Pericellular distribution of crystals $(C)$ and intramatrical lipidic debris $(L)$ in the superficial zone of metatarsal articular cartilage. (Patient 61 years; unstained section.) 
section. Crystals were frequently observed within chondrocyte territorial matrix, often in close proximity to the plasma membrane; however, crystals were not observed in living chondrocytes. In deeper zones, magnesium whitlockite crystals were rarely observed. Crystal deposition when encountered was, in the main, perilacunar, amongst areas of lipidic debris.

The density of deposition showed much variability between joint sites, with no site reaching the greatest densities observed in normal femoral head articular cartilage. A five point qualitative grading scale (table 2) was devised to compare crystal distribution in tissues from different sites. In the knee, whilst articular cartilage from both the femoral condyle (grade 2) and the tibial plateau had crystals present, deposition in the tibial plateau tissue was very sparse (grade 1). A small number of specimens from several smaller joints were examined. Crystal deposition density in cartilage from the proximal ulna and radial head was similar to that in the femoral condyle samples (grade 2-3). In samples from the remaining sites, deposition was more sparse than this, with the least density observed in samples of carpal and phalangeal cartilage (grade 1) (fig 2D). No crystals were observed in peripheral osteophytes from OA femoral heads or epiphysial growth cartilage.

Despite occasional focal densities and dense banding of crystals in the superficial zone matrix, there was no evidence of structural disruption of collagen fibril orientation by crystals in normal articular cartilage, nor was there any evidence of chondrocyte degeneration induced by crystal deposition. Crystals appeared to be present in the interfibrillar space without disrupting the overall fibrillar arrangement.

\section{Discussion}

Previous studies using electron diffraction and $x$ ray diffraction techniques have shown crystals with the same morphology, elemental composition, calcium to phosphorus ratio, and size range to be magnesium whitlockite. ${ }^{24} 29$ The positive identification of crystals in this study using the above criteria is considered sound. The results of this study highlight the extent of magnesium whitlockite crystal deposition in human articular cartilage.

Table 2 Criteria for qualitative grading of crystal deposition density

\begin{tabular}{ll}
\hline Grade & Definition \\
\hline 0 & Crystals not observed. \\
1 & $\begin{array}{l}\text { At least one crystal observed, searching necessary. } \\
\text { Crystals present in a diffuse distribution, no apparent } \\
\text { pattern, regular encounters, extensive searching not } \\
\text { necessary. }\end{array}$ \\
3 & $\begin{array}{l}\text { Crystals present in localised groupings, generally } \\
\text { pericellular to chondrocytes plus a diffuse } \\
\text { intermittent band. }\end{array}$ \\
$\begin{array}{c}\text { Crystals effectively form a continuous band, running } \\
\text { parallel with, and immediately below the articular } \\
\text { surface; local patchiness may be observed in the } \\
\text { band at greater magnifications. }\end{array}$ \\
\hline
\end{tabular}

This work supports and broadens the original limited studies of Ali et $a l^{91021}$ and Stockwell et al. ${ }^{19}{ }^{20}$ With the exception of these authors, such crystal deposition in articular cartilage has not been previously reported, although the reports of the deposition of calcified bodies in human meniscus by Ghadially and Lalonde ${ }^{30}$ and of tricalcium phosphate in articular cartilage by Bardin et $a l^{22}$ are most closely related. A number of points may be raised in an attempt to explain this apparent oversight.

The ultrastructural study of normal human femoral head articular cartilage-a site where deposition has been observed at its most dense-is limited. Ghadially ${ }^{31}$ commented that knowledge of the fine structure of normal articular cartilage is derived largely from a study of animal material, particularly rabbit, with more limited studies of human cartilage from fibrillated and normal looking OA specimens, juvenile specimens taken at autopsy and young adult specimens surgically obtained. Many of these studies were based on specimens from the femoral condyle-a site which, in this study, exhibited a lower maximum crystal deposition density than superior region femoral head specimens. ${ }^{23}$ The commonly used thin section stain uranyl acetate, and distilled water, routinely used to float thin sections away from the ultratome knife edge, both showed a tendency towards crystal loss. ${ }^{32}{ }^{33}$ Uranyl acetate and lead citrate staining imparts greater electron density to matrix components in thin section, possibly concealing the presence of crystals in cases of sparse deposition. With this in mind, reexamination of early studies of human articular cartilage $^{34}$ reveals electron densities amongst stained lipid debris bearing an arguable resemblance to 'cuboid' crystals.

Distribution of crystal deposition in this study conformed to that described for normal femoral head articular cartilage, ${ }^{23}$ the main difference being the density of deposition at different locations. The earlier study demonstrated an association between load bearing and crystal density around the femoral head. ${ }^{23}$ Evidence for the influence of load bearing stresses may be extrapolated from this study. Mechanical loading exerts a major influence on articular cartilage. ${ }^{35}$ It has been suggested that mechanical stress is involved in the regulation of chondrocyte metabolism. ${ }^{37}$ Whilst crystals were present in cartilage from all joint sites examined, the density of such deposition was always less than in the superior region femoral head as determined by the qualitative grading system. This was most noticeable in specimens from the smaller, more peripheral joint sites which are normally subject to lower load bearing stresses. ${ }^{38}$

Magnesium whitlockite deposition has been reported in a number of biological calcifications, both as calculi and in tissues. The most common of these are orally associated, with sites including dental calculi, ${ }^{39}$ arrested carious dentine, ${ }^{40}$ and sialoliths. ${ }^{41}$ Whitlockite has also been reported in urinary calculi, ${ }^{42}$ though this is considered a minor component 
in such situations. Deposition of whitlockite within tissues has been reported at various sites including aortic valvular tophi, ${ }^{43}$ pulmonary calcifications, ${ }^{44}$ and in cartilage from the nasal septum, trachea, epiglottis, and intervertebral disc. ${ }^{45}$ Marked differences in magnesium content have been reported between whitlockites found in calculi and those from cartilages. ${ }^{45}$ The magnesium content of the whitlockite crystals in articular cartilage corresponds with those of tracheal and intervertebral disc cartilage. ${ }^{24}$ The pathological nature of these depositions appears at odds with the current report of magnesium whitlockite deposition in apparently normal tissue.

The presence of these crystals requires consideration of their role in articular cartilage, physiological or pathological. The demonstration of crystal deposition in articular cartilage from normal adolescent to elderly cartilage in this study, suggests that they do not, per se, pose a pathological risk to the tissue.

This may indicate that they are the result of opportunistic deposition, with no defined function. Their circumstantial association with intramatrical lipidic debris may relate crystal deposition to the removal of material generated from chondrocyte necrosis from the extracellular matrix to the synovial fluid, a function considered by Ghadially. ${ }^{31}$ This would provide an opportunity for further speculation on crystal deposition: first, providing possible means of damping ion fluxes created by cell necrosis, minimising the effects on the pericellular environment and second, raising the question, do crystals stay at the site of formation, or is there a migration to the articular surface as suggested for necrotic debris? ${ }^{31}$ The existence of a crystal band in the superficial zone may support the latter.

The possibility of the involvement of subarticular matrical lipid in boundary lubrication-the formation of an adsorbed protective layer on articulating surfaces-has been raised. ${ }^{46}{ }^{47}$ If lipid does act as a boundary lubricant, an involvement in crystal formation may reduce such activity. In the presence of synovial fluid, with the potential for boundary lubrication from hyaluranon, ${ }^{48}$ it would be difficult to envisage a significant decrease in the coefficient of friction resulting from a loss of lipid as suggested. An increase in the coefficient of friction of cartilage samples has been reported in conjunction with increased incidence of crystal deposition, nominally CPPD, and severity of tissue fibrillation, although the relative contribution of either factor was not determined. ${ }^{49}$

The presence of crystals in articular cartilage may alter tissue compliance. It would seem unlikely that the crystal deposition observed in this study, being primarily at the articular surface, would significantly alter the load spreading ability of the tissue. More pertinent may be the local differences in physical properties between cartilage matrix and crystals, providing potential for disruption of articular surface integrity. A correlation between CPPD crystal deposition and severity of fibrillation has been reported by Clift et $a l^{49}$ however, no evidence for the correlation of fibrillation with magnesium whitlockite crystal deposition was observed in this study.

In conclusion, magnesium whitlockite crystal deposition has been demonstrated in articular cartilage across a broad age range at several joint sites. If an apparently opportunistic mode of crystal deposition is accepted, a role as an aggravator of pathological degeneration via an amplification loop, similar to that described by Dieppe and Calvert, ${ }^{15}$ would seem plausible. The potential for such a role may be clarified by further study.

This work was funded by the Arthritis and Rheumatism Council, UK. We are grateful to Action Research for provision of the transmission electron microscope.

1 Freemont A J. Arthritis. In: Salisbury J R, Woods C G, Byers P D, eds. Diseases of bone and joints. London: Byers P D, eds. Diseases of bone

2 Moskowitz R W. Diseases associated with the deposition of CPPD or Hydroxapatite. In: Kelley W N, Harris E D Jr, Ruddy S, Sledge C B, eds. Textbook of rheumatology, 4th edn. Philadelphia: W B Saunders, 1993; 1337-54

3 Dieppe P A, Huskisson E C, Crocker P, Willoughby D A. Apatite deposition disease: a new arthropathy. Lancet 1976; 1 : 266-8.

4 McCarty D J, Lehr J R, Halverson P B. Crystal populations in human synovial fluid. Arthritis Rheum 1983; 26: $1220-4$.

5 Faure G, Netter P, Malaman B, Steinmetz J, Duheille J, Gaucher A. Scanning electron microscopic study of microcrystals implicated in human rheumatic diseases. microcrystals implicated in human rheumatic

6 Faure G, Daculsi G, Netter P, Gaucher A, Kerebel B. Apatites in heterotopic calcifications. Scanning Electron Microscopy 1982; IV: 1629-34

7 Schumacher H R, Cherian P V, Reginato A J, Bardin T, Rothfuss S. Intra-articular apatite crystal deposition. Ann Rheum Dis 1983; 42 (suppl): 54-9.

8 McCarty D J, Gatter R A. Recurrent acute inflammation associated with focal apatite crystal deposition. Arthritis Rheum 1966; 9: 804-19.

9 Ali S Y, Griffiths S. New types of calcium phosphate crystals in osteoarthritic cartilage. Semin Arthritis Rheum 1981;11 (suppl 1): 124-6.

10 Ali S Y. Apatite-type crystal deposition in articular cartilage. Scanning Electron Microscopy 1985; IV: 1555-66.

11 Howell D S. Crystal deposition disease. In: Wright V, ed. Topical reviews in rheumatic disorders 2. Bristol: PSG Wright, 1982; 75-96.

12 Halverson P B, McCarty D J. Identification of hydroxyapatite crystals in synovial fluid. Arthritis Rheum 1979; 22: 389-95.

13 Schumacher H R, Miller J L, Ludvico C, Jessar J A. Erosive arthritis associated with apatite crystal deposition. Arthritis Rheum 1981; 42 (suppl): 54-9.

14 Ohira $T$, Ishikawa $\mathrm{K}$. Hydroxyapatite deposition in osteoarthritic articular cartilage of the proximal femoral head. Arthritis Rheum 1987; 30: 651-60.

15 Dieppe P A, Calvert P. Crystals and joint disease. London: Chapman and Hall, 1983.

16 Paul H, Reginato A J, Schumacher H R. Alizarin red S-staining as a screening test to detect calcium S-staining as a screening test to detect calcium
compounds in synovial fluid. Arthritis Rheum 1983; 26: 191-200.

17 McCarty D J, Silcox D C, Coe F, et al. Diseases associated with calcium pyrophosphate dihydrate crystal deposition: a controlled study. Am F Med 1974; 56: 704-14

18 Dieppe P A, Doherty M, MacFarlane D G, Hutton C W, Bradfield J W, Watt I. Apatite associated destructive arthritis. Br $\mathcal{F}$ Rheumatol 1984; 23: 84-91.

19 Marante I, MacDougall R, Ross A, Stockwell R A. Ultrastructural observations of crystals in articular cartilages of aged human hip joints. Ann Rheum Dis 1983; 42 (suppl): 96-7.

20 Stockwell R A. Distribution of crystals in the superficial zone of elderly human articular cartilage of the femoral head in subcapital fracture. Ann Rheum Dis 1990; 49: 231-5.

21 Rees J A, Ali S Y, Mason A Z. Scanning electron microscopy and microanalysis of 'cuboid' crystals in human articular cartilage. In: Ali S Y, ed. Cell mediated calcification and cartilage. In: Ali S Y, ed. Cell mediated calcification and matrix vesicles. Am.
$\mathrm{BV}, 1986 ; 365-71$.

22 Bardin T, Lansaman J, Bucki B, et al. Tricalcium phosphate crystal identification in human cartilage. An ultrastructural elemental analysis. Arthritis Rheum 1993; 36: S161.

23 Scotchford C A, Greenwald S, Ali S Y. Calcium phosphate crystal distribution in the superficial zone of human femoral head articular cartilage. $\mathcal{F}$ Anat 1992; 181: 293-300. 
24 Scotchford C A, Ali S Y. The isolation and characterization of magnesium whitlockite crystals from human articular cartilage. Osteoarthritis and Cartilage. In press.

25 Elliot J C. Structure and chemistry of the apatites and other calcium phosphates. Amsterdam: Elsevier, 1994.

26 Joy D, Maher E M. Sensitivity limits for thin specimen x-ray analysis. Scanning Electron Microscopy 1977; I 325-34.

27 Russ J C. The direct element ratio model for quantitative analysis of thin sections. In: Hall $\mathrm{T} A$, Echlin $\mathrm{P}$ Kaufman R, eds. Microprobe analysis as applied to cells and tissues. London: Academic Press, 1974; 269-76

28 Klein C P A T, Patka P, den Hollander W. A histological comparison between hydroxylapatite and b-whitlockite macroporous ceramics implanted in dog femora. The Third World Biomaterials Congress 1988; 67.

29 Scotchford C A, Ali S Y. Calcium phosphate microcrystal deposition in articular cartilage: characterization by XRMA. Micron Microscop Acta 1992; 23: 383-4.

30 Ghadially $\mathrm{F}$ N, Lalonde J-M A. Intramatrical lipidic debris and calcified bodies in human semilunar cartilages. $\mathcal{f}$ Anat and calcified bodies in

31 Ghadially F N. Fine structure of synovial joints. London: Butterworth and Co. Ltd, 1983.

32 Bishop M A, Warshawsky H. Electron microscopic studies on the potential loss of crystallites from routinely processed sections of young enamel in the rat incisor. Anat $\operatorname{Rec} 1$ 1982; 202: 177-86

33 Arsenault A L, Hunziker E B. Electron microscopic analysis of mineral deposits in the calcifying epiphyseal growth plate. Calcif Tissue Int 1988; 42: 119-26.

34 Ghadially F N, Meachim G, Collins D H. Extra-cellular lipid in the matrix of human articular cartilage. Ann Rheum Dis 1965; 24: 136-46.

35 Sah R L Y, Kim Y J, Doong J Y, Grodzinsky A J, Plaas A H, Sandy J D. Biosynthetic response of cartilage
explants to dynamic compression. F Orthop Res 1989; 7: 619-36.

36 Van Campen G P J, Van de Stadt R J. Cartilage and chondrocyte responses to mechanical loading in vitro. In Helminen H J, Kiviranta I, Tammi M, Saamanen A-M, Paukkonen K, Jurvelin J, eds. foint loading. Bristol: Wright Brothers, 1987; 112-25.
37 Stockwell R A. Structure and function of the chondrocyte under mechanical stress. In: Helminen $\mathrm{H} J$, Kiviranta $\mathrm{I}$ Tammi M, Saamanen A-M, Paukkonen K, Jurvelin J, eds. foint loading. Bristol: Wright Brothers, 1987; 126-48.

38 Paul J P. Approaches to design. Force actions transmitted by joints in the human body. Proc $R$ Soc Lond [Biol] 1976; 192: $163-72$.

39 Sakae $T$, Yamamoto $H$, Mishima $H$, Matsumoto $T$, Kozawa Y. Morphology and chemical composition of dental calculi mainly composed of whitlockite. Scanning Microscopy 1989; 3: 855-60.

40 Schupbach P, Lutz F, Guggenheim B. Human root caries histopathology of arrested lesions. Caries Res 1992; 26 153-64.

41 Burstein L S, Boskey A L, Tannenbaum P J, Posner A S, Mandel I R. The crystal chemistry of submandibular and parotid salivary gland stones. F Oral Pathol Med 1979; 8 284-91.

42 Verplaetse $H$, Verbeeck R M H, Minnaert H, Oosterlinck W. Solubility of inorganic kidney stone components in the presence of acid-base sensitive complexing agents. Eur Urol 1985; 11: 44-51.

43 Gawoski J M, Balogh K, Landis W J. Aortic valvular tophus: identification by X-ray diffraction and calcium

44 Bestetti-Bosisio M, Cotelli F, Schaffino E, Sorgato G Schmid C. Lung calcification in long term dialysed patients: a light and electron microscopic study. Histopathology 1984; 8: 69-79.

45 Rowles S L. The precipitation of whitlockite from aqueous solutions. Bull Soc Chim 1968; 1797-1802.

46 Swanson S A V. Friction, wear and lubrication. In: Freeman M A R, ed. Adult articular cartilage. Tunbridge Wells: Pitman Medical, 1979; 415-60.

47 Little T, Freeman M A R, Swanson S A V. Experiments on friction in the human hip joint. In: Wright $\mathrm{V}$, ed. Lubrication and wear in joints. London: Sector, 1969; Lubrica $110-4$.

48 Maroudas A. Physicochemical properties of articular cartilage. In: Freeman M A R, ed. Adult articular cartilage. Tunbridge Wells: Pitman Medical, 1979; 215-90.

49 Clift S E, Harris B, Dieppe P A, Hayes A. Frictiona response of articular cartilage containing crystals. Biomaterials 1989; 10: 329-34. 